\title{
PENERAPAN TEXT MINING UNTUK MELAKUKAN CLUSTERING DATA TWEET AKUN BLIBLI PADA MEDIA SOSIAL TWITTER MENGGUNAKAN K-MEANS CLUSTERING
}

\author{
Syiva Multi Fani ${ }^{1}$, Rukun Santoso ${ }^{2}$, Suparti $^{3}$ \\ 1,2,3 Departemen Statistika, Fakultas Sains dan Matematika, Universitas Diponegoro \\ fani.syiva32@gmail.com
}

\begin{abstract}
Social media is computer-based technology that facilitates the sharing of ideas, thoughts, and information through the building of virtual networks and communities. Twitter is one of the most popular social media in Indonesia which has 78 million users. Businesses rely heavily on Twitter for advertising. Businesses can use these types of tweet content as a means of advertising to Twitter users by Knowing the types of tweet content that are mostly retweeted by their followers. In this study, the application of Text Mining to perform clustering using the K-means clustering method with the best number of clusters obtained from the Silhouette Coefficient method on the @ bliblidotcom Twitter tweet data to determine the types of tweet content that are mostly retweeted by @bliblidotcom followers. Tweets with the most retweets and favorites are discount offers and flash sales, so Blibli Indonesia could use this kind of tweet to conduct advertising on social media Twitter because the prize quiz tweets are liked by the @bliblidotcom Twitter account followers.
\end{abstract}

Keywords: Advertising, Blibli Indonesia, Clustering, K-means, Silhouette Coefficient, Text Mining, Twitter.

\section{PENDAHULUAN}

Twitter merupakan salah satu media sosial paling populer di Indonesia. Berdasarkan laporan Wearesocial Hootsuite pengguna media sosial Twitter di Indonesia mencapai 52\% dari jumlah pengguna internet atau mencapai 78 juta pengguna [8]. Pengguna Twitter dapat mengirimkan pesan pendek dengan 140 karakter yang disebut dengan tweet. Twitter memiliki akses yang dinamakan platform API (Application Programming Interface) untuk memperoleh data dengan cepat dan dalam jumlah yang banyak untuk keperluan analisis [15].

Pelaku bisnis sangat mengandalkan Twitter untuk membantu memasarkan produk atau layanan yang mereka miliki agar dapat dikenal oleh konsumen. Blibli merupakan salah satu pelaku bisnis bidang e-commerce di Indonesia yang menggunakan media sosial Twitter sebagai sarana untuk melakukan periklanan. Username @bliblidotcom di Twitter telah memiliki jumlah followers sebanyak 501,3 ribu orang dan jumlah tweet sebanyak 65,3 ribu tweets. Dengan menemukan jenis konten tweet yang banyak dilakukan retweet oleh followers dari Blibli, diharapkan semakin banyak pengguna Twitter yang menjadi konsumen dari Blibli.

Pada penelitian ini dilakukan clustering menggunakan software R. Metode clustering yang digunakan adalah metode $K$-means clustering untuk mengelompokkan data tekstual berdasarkan kesamaan konten yang dimiliki ke dalam beberapa cluster. Clustering dilakukan pada data jenis konten tweet akun Twitter @ bliblidotcom yang disukai oleh followers akun Twitter@bliblidotcom berdasarkan perhitungan rata-rata jumlah favorite dan retweet masing- masing cluster. Hal tersebut dikarenakan jika pengguna Twitter menyukai suatu tweet maka kemungkinan yang akan dilakukan pengguna tersebut adalah menekan tombol favorite atau melakukan retweet. Hasil clustering data tweet dapat digunakan untuk menunjang kegiatan advertising atau periklanan Blibli pada media sosial Twitter. Pelaku bisnis dapat memanfaatkan followers akun Twitter mereka sebagai sarana untuk melakukan advertising. Dengan menggunakan perintah retweet dan favorite pada Twitter, followers dapat menyebarkan tweet yang dibuat oleh pelaku bisnis. Dengan menemukan jenis konten tweet yang banyak disukai oleh followers dari @bliblidotcom, diharapkan semakin banyak pengguna Twitter yang menjadi konsumen dari Blibli Indonesia. 


\section{TINJAUAN PUSTAKA}

\subsection{Text Mining}

Text mining adalah proses ekstraksi pola (informasi dan pengetahuan yang berguna) dari sejumlah sumber data melalui identifikasi pola yang menarik. Pada kasus text mining, sumber data adalah kumpulan data tekstual yang tidak terstruktur pada dokumen [3]. Text mining bertujuan untuk menemukan informasi yang tidak diketahui, sesuatu yang belum diketahui dan belum dapat ditulis [5].

\subsection{Ekstraksi Tweets}

Application Programming Interface (API) berfungsi sebagai penghubung antara sistem yang dibangun dengan twitter yang memungkinkan pengguna untuk mengekstrak data dengan pemrograman. Untuk dapat mengeksraksi tweet dari Twitter API diperlukan proses autentifikasi. Autentifikasi adalah suatu proses validasi atau pembuktian terhadap identitas seorang pengguna pada saat akan mengakses sebuah system [9]. Proses autentifikasi pada Twitter API ini menggunakan API key, API secret key, access token, dan access token secret yang dijadikan sebagai kode akses untuk memasuki sistem tersebut.

\subsection{Text Preprocessing}

Data tweet yang telah diambil dari sosial media twitter masih merupakan data mentah dengan karakteristik teks memiliki dimensi yang tinggi, terdapat noise pada data, dan terdapat struktur teks yang tidak baik[4]. Dalam text preprocessing dilakukan pengurangan kata-kata tidak penting, tidak mempunyai arti dari database teks atau dokumen, sehingga membuat data lebih terstruktur dan siap untuk diolah [7].

Berdasarkan penelitian yang dilakukan [17] langkah-langkah text preprocessing adalah sebagai berikut:

1. Case folding adalah penyeragaman bentuk huruf atau mengubah semua karakter huruf besar (uppercase) menjadi karakter huruf kecil (lowercase) pada dokumen teks.

2. Remove URL adalah penghapusan link URL (Uniform Resource Locator) yang terdapat pada teks. Tweet yang mengandung kata "http://" merupakan tweet dengan link URL.

3. Unescape HTML adalah penghapusan HTML (HyperText Markup Language) yang menggunakan tanda-tanda tertentu dan menghapus jejak karakter yang bisa dianggap sebagai markup.

4. Remove mention adalah penghapusan mention (penyebutan pengguna lain) pada data tweet perlu dilakukan karena umumnya tidak mengandung informasi yang penting.

5. Remove number adalah penghapusan semua angka yang terdapat pada teks.

6. Remove punctuation adalah penghapusan semua tanda baca selain alphabet pada teks.

\subsection{Feature Selection}

Feature selection merupakan tahapan untuk mengurangi dimensi dari data tekstual sehingga hasil dari data teks memiliki kualitas yang lebih baik[9]. Langkah-langkah yang dilakukan antara lain:

1. Stemming adalah proses mentrasformasikan kata-kata dalam dokumen menjadi kata akarnya (root word) atau kata dasar[1].

2. Stopword adalah sebagian kata dalam suatu korpus yang muncul dalam jumlah besar dan dianggap tidak penting atau tidak menggambarkan isi dari sebuah kalimat. Contoh dari stopwords adalah kata "yang", "dan", "dari", "ke", "ini", dan sebagainya. Stopword dihilangkan untuk mempercepat proses pengolahan data teks dan mendapatkan informasi yang relevan[16]. 
3. Tokenizing merupakan proses pemotongan teks berdasarkan tiap kata yang menyusunnya berdasarkan karakter spasi[11].

\subsection{Pembobotan Data}

Term Frequency-Inverse Document Frequency (TF-IDF) adalah metode yang digunakan untuk menghitung bobot setiap kata yang telah dianalisis. Model pembobotan TFIDF merupakan metode yang mengintegrasikan model term frequency (TF) dan inverse document frequency (IDF). Tahap TF merupakan cara menentukan bobot setiap kata (term) pada suatu dokumen berdasarkan jumlah kemunculannya dalam dokumen tersebut. Selanjutnya tahap IDF yaitu pengurangan dominasi kata yang sering muncul di berbagai dokumen. TF-IDF dihitung menggunakan persamaan sebagai berikut [12]:

$$
W_{i, j}=\frac{n_{i, j}}{\sum_{i} n_{i, j}} \cdot \log _{2} \frac{D}{d_{i}}
$$

Keterangan:

$W_{j, i} \quad:$ Pembobotan TF-IDF untuk term ke j pada dokumen ke i.

$n_{j, i} \quad$ : Jumlah kemunculan term ke j pada dokumen ke i.

$\sum_{k} n_{k, i}$ : Jumlah kemunculan seluruh term pada dokumen ke i.

$D \quad$ : Banyaknya dokumen yang dibangkitkan.

$d_{j} \quad$ : Banyaknya dokumen yang mengandung term ke $\mathrm{j}$.

\subsection{Silhouette Coefficient}

Silhouette coefficient merupakan salah satu metode yang digunakan untuk melihat kualitas dan kekuatan cluster, seberapa baik suatu objek ditempatkan dalam suatu cluster. Metode ini merupakan gabungan dari metode cohesion dan separation [6].

Dalam perhitungan nilai silhouette coefficient, terdapat komponen yaitu $a_{i}$ dan $b_{i}$. Komponen $a_{i}$ adalah rata-rata jarak data ke-i terhadap semua data lainnya dalam satu cluster, sedangkan komponen $b_{i}$ adalah hasil perhitungan rata-rata jarak data ke-i terhadap semua data lainnya yang tidak dalam satu cluster, kemudian diambil nilai terkecil. Nilai silhouette coefficient berada pada rentang -1 hingga 1. Semakin besar nilai silhouette coefficient menunjukkan bahwa cluster tersebut merupakan cluster terbaik [6]. berikut :

Berdasarkan penelitian [6], tahapan perhitungan silhouette coefficient adalah sebagai

1. Hitung rata-rata jarak dari suatu data misalkan i dengan semua data lain yang berada dalam satu cluster $\left(a_{i}\right)$.

$$
a_{i}^{j}=\frac{1}{m_{j}-1} \sum_{r=1}^{m_{j}} d\left(x_{i}^{j}, x_{r}^{j}\right)
$$

2. Hitung rata-rata jarak dari data $i$ tersebut dengan semua data di cluster lain

$$
d_{i}^{j}=\frac{1}{m_{n}} \sum_{r=1}^{m_{j}} d\left(x_{i}^{j}, x_{r}^{m j}\right)
$$

3. Pengambilan nilai terkecil dari $d_{i}^{j}$ sebagai nilai $b_{i}^{j}$

$$
b_{i}^{j}=\min d_{i}^{j}
$$

4. Penghitungan nilai silhouette coefficient data

$$
S_{i}^{j}=\frac{b_{i}^{j}-a_{i}^{j}}{\max \left\{a_{i}^{j}, b_{i}^{j}\right\}}
$$

5. Nilai silhouette coefficient dari sebuah cluster

$$
S_{j}=\frac{1}{m_{j}} \sum_{i=1}^{m_{j}} S_{i}^{j}
$$

6. Nilai silhouette coefficient global ditentukan dengan menghitung rata-rata nilai silhouette coefficient semua cluster dengan rumus :

$$
S_{g}=\frac{1}{k} \sum_{j=1}^{k} S_{j}
$$

Keterangan : 


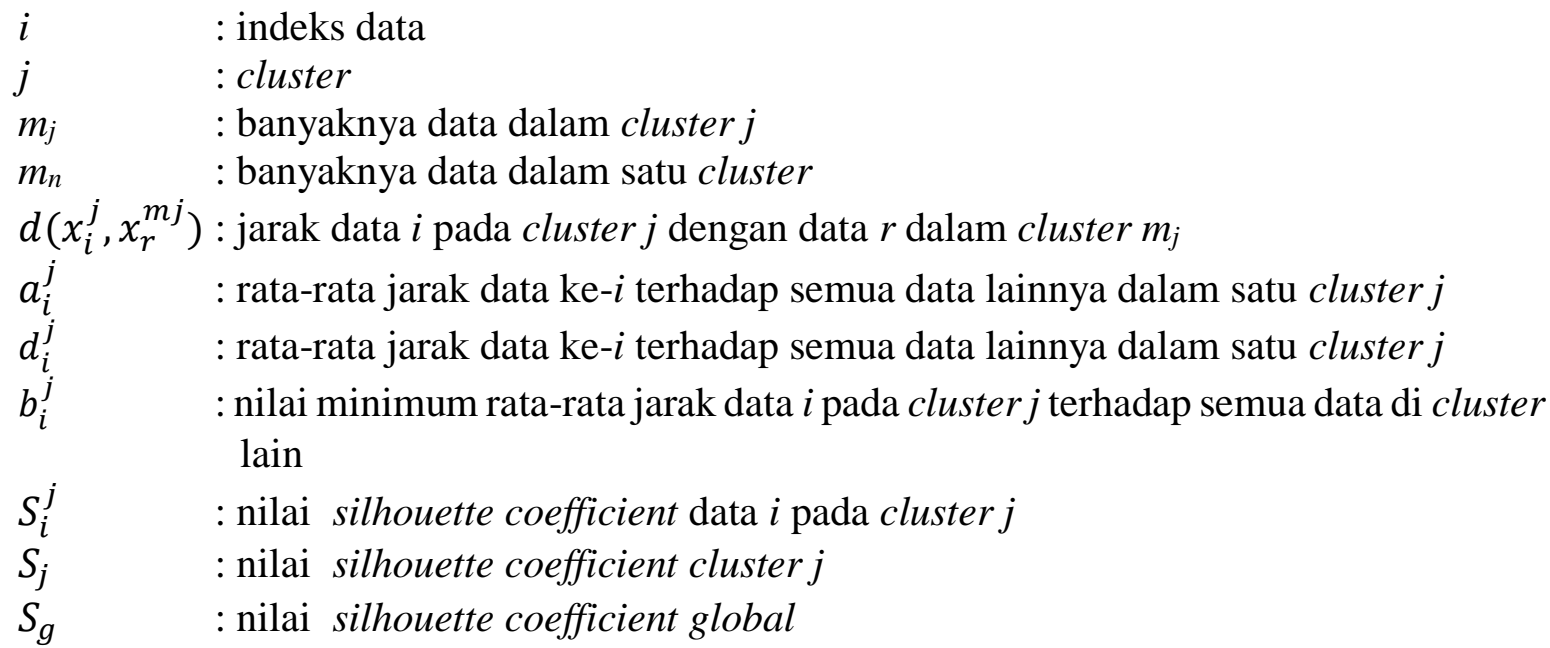

\subsection{K-Means Clustering}

Analisis cluster digunakan untuk mengklasifikasi obyek atau kasus (responden) ke dalam kelompok yang relatif homogen yang disebut cluster, obyek atau kasus dalam setiap kelompok cenderung mirip satu sama lain dan tidak sama dengan obyek dari cluster lainnya [13]. K-Means merupakan salah satu metode analisis cluster yang melakukan partisi set data ke dalam sejumlah K cluster yang sudah ditetapkan di awal[18].

Proses clustering dimulai dengan mengidentifikasi data yang akan dicluster, $x_{i j}$ $(\mathrm{i}=1, \ldots, \mathrm{n} ; \mathrm{j}=1, \ldots, \mathrm{m})$ dengan $\mathrm{n}$ adalah banyaknya data yang akan dicluster dan $\mathrm{m}$ adalah banyaknya variabel. Pada awal iterasi, pusat setiap cluster ditetapkan secara bebas, $c_{k j}$ $(\mathrm{k}=1, \ldots, \mathrm{s} ; \mathrm{j}=1, \ldots, \mathrm{m})$ dengan $\mathrm{k}$ adalah banyaknya cluster. Kemudian dihitung jarak antara setiap data dengan setiap pusat cluster. Untuk melakukan penghitungan jarak data ke-i (xi) pada pusat cluster ke-k (ck), diberi nama D(x,c), dapat digunakan formula Euclidean, seperti persamaan (8) yaitu :

$$
D(x, c)=d_{i k}=\sqrt{\sum_{j=1}^{m}\left(x_{i j}-c_{k j}\right)^{2}}
$$

Suatu data akan menjadi anggota dari cluster ke-k apabila jarak data tersebut ke pusat cluster ke-k bernilai paling kecil jika dibandingkan dengan jarak ke pusat cluster lainnya. Selanjutnya, kelompokkan data-data yang menjadi anggota pada setiap cluster.

Nilai pusat cluster yang baru dapat dihitung dengan cara mencari nilai rata-rata dari data-data yang menjadi anggota pada setiap cluster tersebut, dengan menggunakan rumus pada persamaan (9) sebagai berikut :

$$
\overline{c_{k j}}=\frac{\sum_{i=1}^{n} x_{i j}^{k}}{p_{k j}}
$$

dengan $x_{i j}^{k} \epsilon$ cluster ke-k

$p_{k j}$ : banyaknya anggota cluster ke-k dari variabel $\mathrm{j}$ (tidak bernilai 0 )

$\overline{c_{k j}}$ : nilai pusat cluster yang baru

Cluster yang baik adalah cluster yang mempunyai homogenitas (kesamaan) yang tinggi antar anggota dalam satu cluster (within cluster) dan heterogenitas yang tinggi antar cluster yang satu dengan cluster lainnya (between cluster) [10].

\subsection{Wordcloud}

Word cloud adalah presentasi grafis dari suatu dokumen, biasanya dihasilkan dengan memetakan kata-kata paling umum dari suatu dokumen dalam dua dimensi ruang, dengan frekuensi kata yang ditunjukkan oleh ukuran hurufnya[2]. Konsep pembuatan word cloud yaitu kata-kata yang memiliki ukuran huruf terbesar merupakan kata yang paling penting dan banyak[14]. 


\section{METODE PENELITIAN}

\subsection{Jenis dan Sumber Data}

Penelitian ini menggunakan data kualitatif berupa 1500 tweet dari timeline akun Twitter @bliblidotcom. Data yang diambil merupakan data tweet tanpa replies. Pengambilan data tweet diperoleh dari API (Application Programming Interface) Twitter yang dilakukan pada tanggal 1 Maret 2020. Data yang diperoleh adalah data pada periode 1 Oktober 2019 sampai 1 Maret 2020.

\subsection{Teknik Pengolahan Data}

Analisis data pada penelitian ini menggunakan metode text mining dan $K$-means clustering dengan bantuan software R i386 3.6.2 dan Microsoft Excel 2013. Adapun langkah-langkah analisis data yang dilakukan adalah sebagai berikut:

1. Extracting tweets, pengambilan 1500 tweets terbaru di media sosial Twitter @bliblidotcom dengan ketentuan tweets tanpa replies. Data diakses melalui Twitter Application Programming Interface (API).

2. Text preprocessing, data teks yang telah diambil diolah melalui beberapa tahap, yaitu case folding, remove URL, unescape $\mathrm{HTML}$, remove mention, remove number, dan remove punctuation.

3. Feature selection, tahapan untuk mengurangi dimensi dari sebuah data teks sehingga hasil memiliki kualitas yang lebih baik. Proses yang dilakukan adalah stemming, stopword removal dan tokenizing.

4. Pembobotan data teks dengan TF-IDF dalam bentuk term-document matrix

5. Penentuan jumlah cluster terbaik yang dilakukan berdasarkan hasil perhitungan nilai Silhouette Coefficient

6. Proses clustering data dengan metode K-Means Clustering

7. Analisis jenis konten tweets pada tiap cluster

8. Interpretasi data dengan word cloud

4. ANALISIS DAN PEMBAHASAN

\subsection{Extracting Tweets}

Extracting tweets bertujuan untuk mengumpulan data teks dari aplikasi Twitter dengan menggunakan Twitter API. Untuk melakukan extracting tweets dibutuhkan empat kode akses, yaitu API Key, API Secret, Access Token, and Access Token Secret. Kode-kode tersebut diperoleh setelah mendaftarkan akun Twitter pada https://developer.Twitter.com/en/apps. Pengambilan 5.000 tweets di akun Twitter @ bliblidotcom dengan ketentuan tweets tanpa replies. Hasil tweets yang diperoleh pada ekstraksi tweets berjumlah 1846 tweets yang kemudian diambil 1500 tweets terbaru untuk dilakukan proses clustering data.

\subsection{Pre-Processing Data}

Proses ini merupakan tahap pengambilan data dan ekstraksi data yang mengubah format asli dan tidak terstruktur menjadi terstruktur agar dapat diolah untuk tahapan berikutnya. Tahapan yang dilakukan diantaranya adalah sebagai berikut:

1. Case Folding

Case folding adalah tahapan mengubah semua huruf besar atau kapital pada data Twitter menjadi huruf kecil semua (lowercase) menggunakan fungsi 'bli.corpus <tm_map(bli.corpus,content_transformer(tolower))'.

2. Remove URL

Remove URL akan menghapus link URL (Uniform Resource Locator) yang terdapat pada data Twitter. Link URL biasanya mengandung kata "http://". Remove URL dilakukan dengan menggunakan fungsi 'removeURL $<-$ function(x) $\operatorname{gsub}(" h \operatorname{ttp}[\wedge[$ :space:]]*", "", x)'. 
3. Unescape HTML

Unescape HTML dilakukan untuk menghapus file HTML (Hyper Text Markup Language) yang menggunakan tanda-tanda tertentu dan menghapus jejak karakter yang bisa dianggap sebagai markup. Unescape HTML dilakukan dengan menggunakan fungsi 'unescapeHTML <- function(x) $\{$ gsub("[^|x01-|x7F]", "', x)\}'.

4. Remove Mention

Remove mention dilakukan untuk menghilangkan kata yang mengandung “@” yang berarti menyebutkan usename pengguna Twitter lain dengan menggunakan fungsi 'removeMention <- function(x)\{gsub("@llw+", "", x)\}'.

5. Remove Number

Semua angka yang terdapat pada dokumen teks akan dihapus dengan menggunakan fungsi 'bli.corpus <- tm_map(bli.corpus, toSpace, "[[:digit:]]")'.

6. Remove Punctuation

Remove punctuation akan menghapus tanda baca yang ada pada data Twitter. Karena penelitian ini hanya mengklasifikasikan data teks, maka selain karakter alphabet akan dihapus dari data Twitter. Remove punctuation dilakukan dengan menggunakan fungsi 'bli.corpus <- tm_map(bli10s.corpus, toSpace, "[[:punct:]]")'.

Tabel 1. Hasil Proses Preprocessing Data

\begin{tabular}{|c|c|c|}
\hline Tweet ke- & Sebelum Preprocessing Data & Sesudah Preprocessing Data \\
\hline 1 & $\begin{array}{l}\text { Heyho! Masuk di bulan Maret, Blibli } \\
\text { langsung kasi promo buat kamu semua yang } \\
\text { suka main games! \#KarenaKamuNo1, } \\
\text { diskon sampai } 65 \% \text { ! Sikats }\end{array}$ & $\begin{array}{l}\text { heyho masuk di bulan maret blibli } \\
\text { langsung kasi promo buat kamu semua } \\
\text { yang suka main games karenakamuno } \\
\text { diskon sampai sikats }\end{array}$ \\
\hline 2 & $\begin{array}{l}\text { Februari segera berakhir. Siap menyongsong } \\
\text { bulan Maret, friends? }<U+0001 F 4 A A>\end{array}$ & $\begin{array}{l}\text { februari segera berakhir siap } \\
\text { menyongsong bulan maret friends }\end{array}$ \\
\hline 3 & $\begin{array}{l}\text { belanja di lebih mudah dan hemat pakai } \\
\text { gopay khusus sampai tanggal maret } \\
\text { blibli fr }\end{array}$ & $\begin{array}{l}\text { belanja di lebih mudah dan hemat pakai } \\
\text { gopay khusus sampai tanggal maret } \\
\text { blibli fr }\end{array}$ \\
\hline
\end{tabular}

\subsection{Feature Selection}

Tahapan ini dilakukan untuk mengurangi dimensi dari sebuah data Twitter dengan menghapus kata-kata yang tidak relevan sehingga proses pengelompokan lebih efektif dan akurat.

\section{Stemming}

Stemming diperlukan untuk memperkecil jumlah indeks yang berbeda dari suatu dokumen dengan cara menghilangkan imbuhan kata yang ada.

\section{Stopword}

Remove stopwords digunakan untuk menghilangkan kata-kata dalam suatu korpus yang muncul dan dianggap tidak menggambarkan isi dari sebuah kalimat. Pemilihan kata yang bermakna dengan menghilangkan kata yang kurang penting dalam membangun model dapat meningkatkan hasil akurasi sistem klasifikasi. Stopwords yang digunakan pada penelitian ini berjumlah 773 kata yang diperoleh dari http://www.ranks.nl/stopwords/indonesian. Serta tambahan stopword sebanyak 1155 kata secara manual dengan menambahkan kata-kata yang tidak penting. Hasil stopword memiliki beberapa tweet yang hanya menyisakan kata-kata yang secara keseluruhan tidak mempunyai makna tertentu. Tweets ini akan dihilangkan pada tahap pembobotan TF.

3. Tokenizing

Proses tokenizing dilakukan untuk memotong teks tiap kata berdasarkan spasi. Tabel 2 merupakan contoh proses tokenizing yang terbentuk setelah dilakukan filtering stopwords. 
Tabel 2. Proses Tokenizing

\begin{tabular}{clll}
\hline No & Sebelum Tokenizing & Sesudah Tokenizing \\
\hline 6 & sehat soyjoy harga & spesial & sehat \\
& soylution active package & soyjoy \\
& & harga \\
& & special \\
& & soylution \\
& & active \\
& & package \\
\hline \hline
\end{tabular}

\subsection{Pembobotan Data}

Pembobotan kata yang digunakan pada penelitian ini adalah Term Frequency-Inverse Document Frequency (TF-IDF). Pembobotan data akan digunakan untuk membangun model klasifikasi. Data yang digunakan sejumlah 962 data yang telah melalui tahap penghapusan tweet yang hanya memiliki 1-3 kata dan tidak memiliki makna.

Tabel 3. Pembobotan dengan Term Frequency Inverse Document Frequency

\begin{tabular}{cccccccccc}
\hline & abadi & absen & acara & accessories & Acer & acmic & action & $\ldots$ & zoom \\
\hline $\begin{array}{c}\text { Tweet } \\
\text { ke-1 }\end{array}$ & 0 & 0 & 0 & 0 & 0 & 0 & 0 & $\ldots$ & 0 \\
$\begin{array}{c}\text { Tweet } \\
\text { ke-3 }\end{array}$ & 0 & 0 & 0 & 0 & 0 & 0 & 0 & $\ldots$ & 0 \\
$\vdots$ & $\vdots$ & $\vdots$ & $\vdots$ & $\vdots$ & $\vdots$ & $\vdots$ & $\vdots$ & $\ddots$ & $\vdots$ \\
$\begin{array}{c}\text { Tweet } \\
\text { ke-1499 }\end{array}$ & 0 & 0 & 0 & 0 & 0 & 0 & 0 & $\ldots$ & 0 \\
\hline
\end{tabular}

\subsection{Silhouette Coefficient}

Penentuan jumlah cluster terbaik yang dilakukan dalam penelitian ini menggunakan metode Silhouette Coefficient dengan menggunakan fungsi 'fviz_nbclust (matriks_kata, kmeans, method = "silhouette", k.max=10)'. Perhitungan nilai Silhouette Coefficient dilakukan untuk data matriks_kata yang merupakan data pembobotan TF-IDF dengan $\mathrm{k}=1$ sampai $\mathrm{k}=10$. Hasil Silhouette Coefficient ditampilkan pada Gambar 1. Pada Gambar 1 terlihat bahwa titik tertinggi terdapat pada $\mathrm{k}=6$ yang berarti jumlah cluster terbaik yaitu 6 . Hasil perhitungan k terbaik digunakan untuk proses clustering dengan $K$-means.

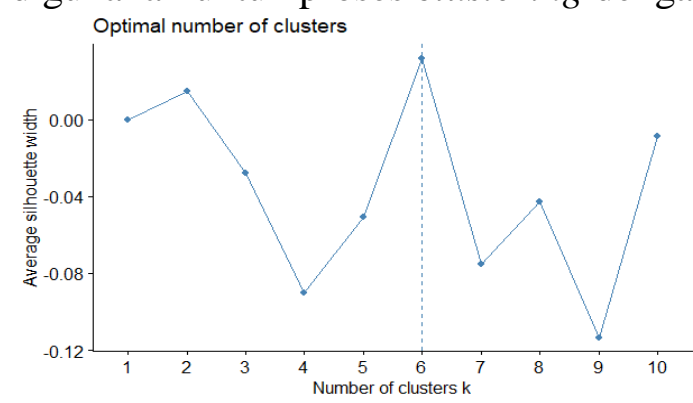

Gambar 1. Nilai Silhouette Coefficient pada Jumlah Cluster 1 sampai 10

\subsection{Analisis Jenis Konten Tweet}

Penentuan jenis konten dari masing-masing cluster tweet dilakukan dengan menganalisis kata yang paling sering muncul pada masing-masing cluster. Kata-kata tersebut akan diambil 10 kata teratas yang paling sering muncul untuk menggambarkan jenis konten tweets pada setiap cluster. Fungsi yang digunakan untuk mengurutkan kata-kata tersebut yaitu ' $\mathrm{p}<-\operatorname{sort}(\operatorname{colSums}(\mathrm{q})$, decreasing=TRUE)'. 
Tabel 4. Hasil Document Term Matrix Pembobotan TF IDF

\begin{tabular}{|c|c|c|}
\hline Cluster & Kata Paling Sering Muncul & Jenis Konten Tweet \\
\hline 1 & $\begin{array}{l}\text { diskon, produk, histeriasyok, harga, spesial, } \\
\text { flash, sale, game, voucher, blogbliblifriends }\end{array}$ & $\begin{array}{l}\text { penawaran diskon flash sale untuk } \\
\text { voucher game dan produk lainnya }\end{array}$ \\
\hline 2 & $\begin{array}{l}\text { jalan, mall, tiket, voucher, weekend, } \\
\text { cashback, diskon, gratis, handphone, } \\
\text { histeriasyok }\end{array}$ & $\begin{array}{l}\text { penawaran-penawaran pada sebuah } \\
\text { mall waktu weekend seperti voucher, } \\
\text { cashback, dan diskon }\end{array}$ \\
\hline 3 & teman, final, pialapresidenesports, regional, & Turnamen Blibli Esport \\
\hline & $\begin{array}{l}\text { kualifikasi, blibliesports, grand, barat, } \\
\text { tanding, timur }\end{array}$ & Championship Indonesia \\
\hline 4 & $\begin{array}{l}\text { earphone, wireless, beats, kabel, kualitas, } \\
\text { aksesoris, canggih, charger, denger, lagu }\end{array}$ & $\begin{array}{l}\text { penawaran barang elektronik } \\
\text { aksesoris handphone seperti charger } \\
\text { dan earphone }\end{array}$ \\
\hline 5 & $\begin{array}{l}\text { libur, foto, kamera, diskon, visa, tiket, } \\
\text { game, hasil, lensa, produk }\end{array}$ & $\begin{array}{l}\text { penawaran produk yang digemari } \\
\text { saat liburan seperti kamera, tiket, } \\
\text { game dan produk lainnya }\end{array}$ \\
\hline 6 & $\begin{array}{l}\text { pasangan, kado, valentine, lagu, diskon, } \\
\text { orang, romantis, sayang, bangun, bucin }\end{array}$ & $\begin{array}{l}\text { penawaran diskon kado valentine } \\
\text { untuk pasangan }\end{array}$ \\
\hline
\end{tabular}

Gambar 2, Gambar 3, Gambar 4, Gambar 5, Gambar 6, dan Gambar 7 menunjukkan visualisasi dari jenis konten tweets pada cluster 1 , cluster 2 , cluster 3, cluster 4, cluster 5 , dan cluster 6.

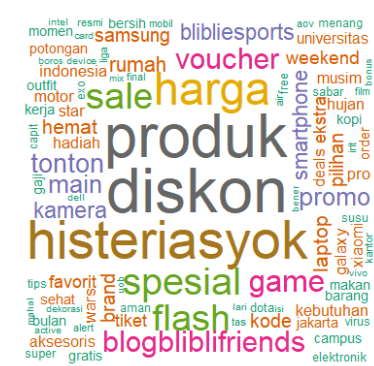

Gambar 2. Word Cloud Cluster 1

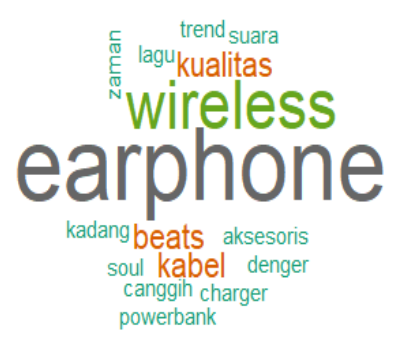

Gambar 5. Word Cloud Cluster 4

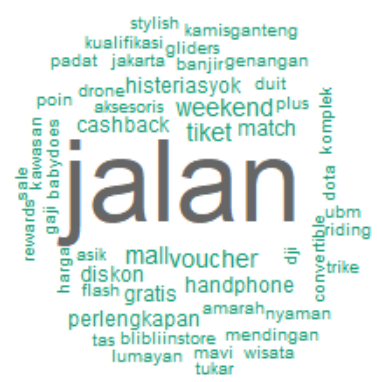

Gambar 3. Word Cloud Cluster 2

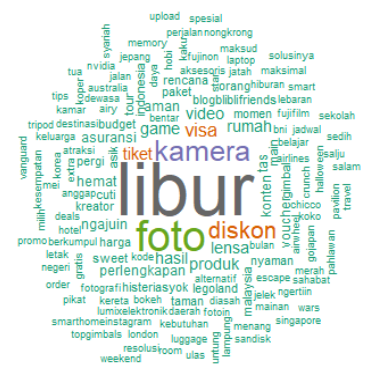

Gambar 6. Word Cloud Cluster 5

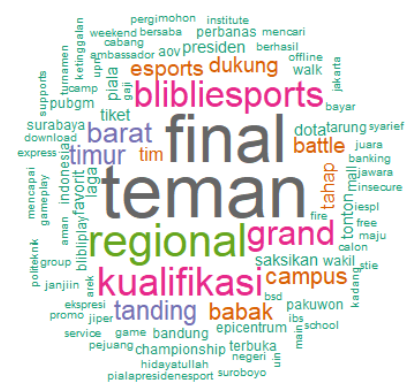

Gambar 4. Word Cloud Cluster 3

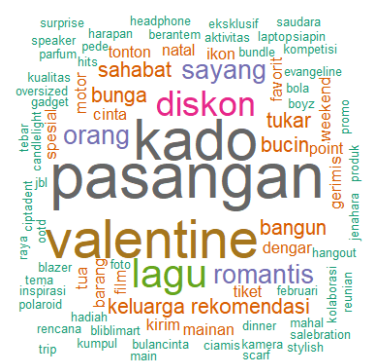

Gambar 7. Word Cloud Cluster 1

\subsection{Analisis Konten yang Disukai Followers Twitter @ bliblidotcom}

Penentuan konten yang disukai oleh followers akun Twitter@bliblidotcom dapat dilakukan berdasarkan perhitungan rata-rata jumlah favorite dan retweet masing- masing cluster. Perhitungan rata-rata jumlah favorite dan retweet untuk masing-masing cluster terlihat pada Tabel 5.

Pada Gambar 8 terlihat bahwa cluster yang memiliki rata-rata favorite dan retweet tertinggi adalah cluster 1 yaitu tweet mengenai penawaran diskon flash sale untuk voucher game dan produk lainnya. Sedangkan cluster yang memiliki rata-rata favorite dan retweet terendah adalah cluster 1 yaitu tweet mengenai penawaran barang elektronik aksesoris handphone seperti charger dan earphone. Blibli Indonesia diharapkan mampu memanfaatkan konten diskon dan flash sale sebagai sarana periklanan semaksimal mungkin. 
Tabel 5. Hasil Perhitungan Rata-Rata Favorite dan Retweet

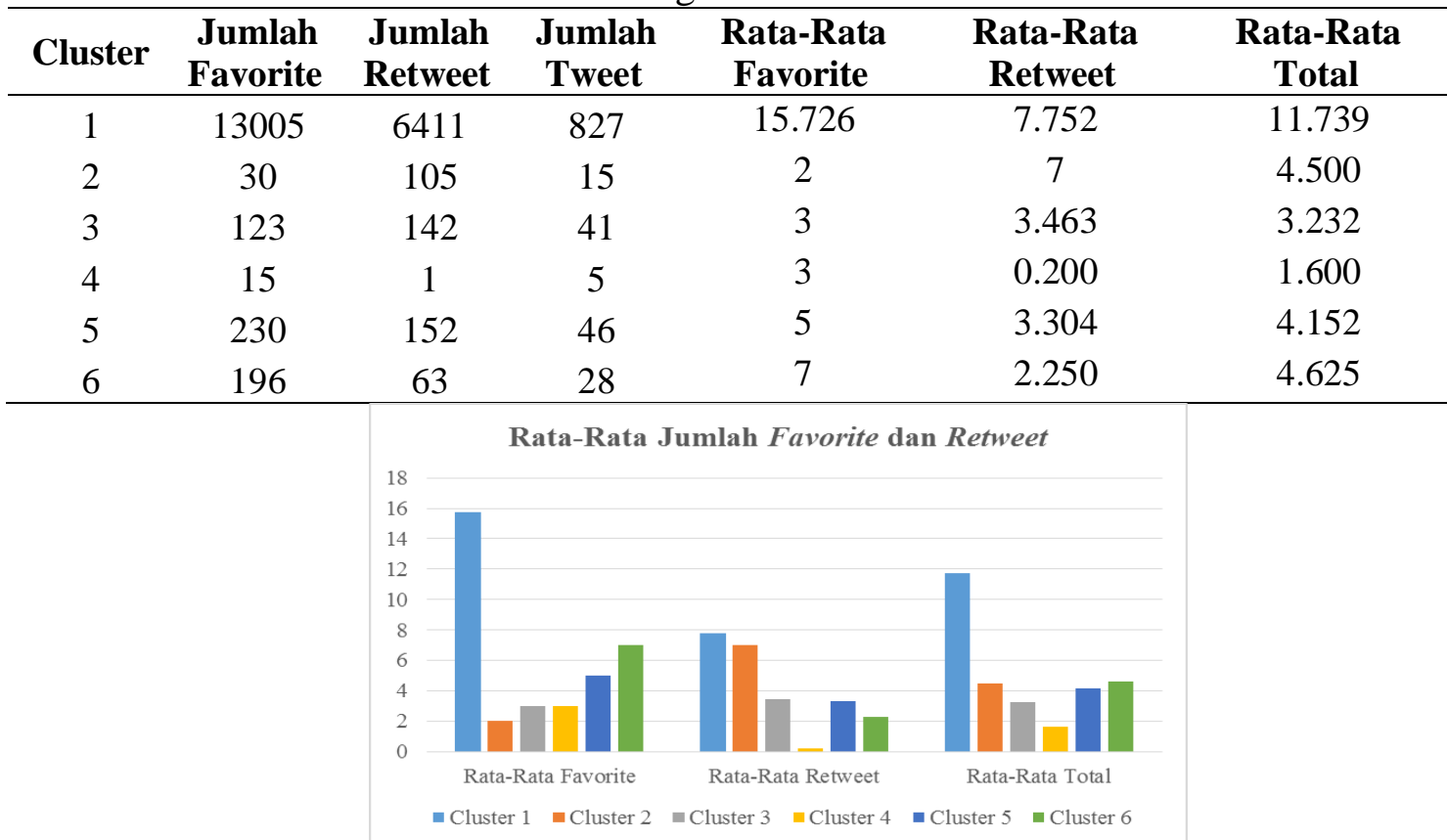

Gambar 8. Grafik Rata-Rata Jumlah Favorite dan Retweet

Masing-masing cluster memiliki tweet dengan jumlah favorite dan retweet paling banyak diantara tweets lain pada cluster tersebut. Tweet tersebut juga memiliki periodenya masing-masing.

Tabel 6. Tweet dengan Jumlah Favorite dan Retweet Paling Banyak pada Tiap Cluster

\begin{tabular}{|c|c|c|c|c|}
\hline Cluster & $\begin{array}{c}\text { Tweet } \\
\text { ke- }\end{array}$ & Isi Tweet & $\begin{array}{l}\text { Jumlah } \\
\text { Favorite } \\
\text { Retweet }\end{array}$ & Tanggal \\
\hline 1 & 944 & $\begin{array}{l}\text { Mimin gak nyangka bisa sedeket ini sama EXO. } \\
\text { Rasanya Mimin seperti sedang bermimpi } \\
<\mathrm{U}+0001 \mathrm{~F} 634>\text { \#EXp1OrationinJKT... } \\
\text { https://t.co/pH41CiGPSC }\end{array}$ & 4260 & $23 / 11 / 2019$ \\
\hline 2 & 917 & $\begin{array}{l}\text { Daripada memberi amarah ke padatnya jalanan, } \\
\text { mendingan mimin bagi-bagi voucher belanja. Pasti } \\
\text { mau kan kamu? Coba b... https://t.co/niI9MXiEYH }\end{array}$ & 143 & $26 / 11 / 2019$ \\
\hline 3 & 306 & $\begin{array}{l}\text { Holaaaaa! Selamat siang pejuang Esports! Sekarang } \\
\text { aku lagi di Grand Final \#PialaPresidenEsports2020 } \\
\text { yang berlangsu... https://t.co/TKophjIzhF }\end{array}$ & 19 & $01 / 02 / 2020$ \\
\hline 4 & 673 & $\begin{array}{l}\text { Lagi nge-trend banget nih earphone wireless dan } \\
\text { kualitasnya ajib! Nah, ini nih alasan kenapa } \\
\text { earphone wireless dig... https://t.co/kCFyVc1hBe }\end{array}$ & 5 & $19 / 12 / 2019$ \\
\hline 5 & 157 & $\begin{array}{l}\text { Sudah cek jadwal libur lebaran? Segerakan } \\
\text { membeli tiket kereta ke kotamu, agar bisa } \\
\text { berkumpul bersama orang tua dan... } \\
\text { https://t.co/1NLn8GSjga }\end{array}$ & 17 & $16 / 02 / 2020$ \\
\hline 6 & 121 & $\begin{array}{l}\text { Gerimis-gerimis, dengerin lagu iKon. Hari Kamis, } \\
\text { harinya diskon! \#KarenaKamuNo1 diskon sampai } \\
50 \% \text { buat yang lagi... https://t.co/4S4i4pjUbi }\end{array}$ & 159 & $20 / 02 / 2020$ \\
\hline
\end{tabular}




\section{KESIMPULAN}

Cluster tweet yang terbentuk adalah konten mengenai aktivitas perbelanjaan, penawaran-penawaran pada sebuah mall, Turnamen Blibli Esport Championship Indonesia, penawaran barang elektronik aksesoris handphone, aktivitas rekreasi, serta penawaran diskon kado valentine.

Jumlah anggota masing-masing cluster kurang merata. Cluster 1 memiliki anggota sebanyak 827, cluster 2 sebanyak 15, cluster 3 sebanyak 41, cluster 4 sebanyak 5, cluster 5 sebanyak 46, dan cluster 6 sebanyak 28. Cluster 1 memiliki paling banyak anggota daripada cluster yang lain karena perbedaan bobot yang cukup jauh dan banyaknya kata yang sama terdapat pada cluster 1 seperti kata "diskon" dan "promo" yang jumlahnya sangat banyak. Sebagian besar tweet yang ditulis oleh akun @bliblidotcom juga memuat tentang aktivitas perbelanjaan yang termasuk dalam cluster 1 .

Setiap cluster memiliki periodenya masing-masing sesuai dengan isi tweet yang disampaikan oleh @bliblidotcom. Cluster 1 banyak terdapat pada periode bulan Desember 2019, cluster 2 banyak terdapat pada periode akhir bulan, cluster 3 berlangsung dari November 2019 sampai Februari 2020, cluster 4 banyak terdapat pada Desember 2019, cluster 5 banyak terdapat pada libur akhir tahun Desember 2019, serta cluster 6 banyak terdapat pada periode Februari 2020.

Strategi yang perlu dilakukan untuk mengolah term kata tersebut agar jumlah anggota cluster lebih seimbang adalah dengan cara pemilihan kata pada proses stemming dan stopwords. Kata-kata yang diolah dalam proses tersebut harus lebih teliti. Pengelompokkan nama-nama merk produk menjadi suatu kategori juga diperlukan agar tidak mempengaruhi perbedaan bobot yang terlalu jauh.

Dari pola yang diperoleh dapat diberikan beberapa saran:

1. Jenis konten dengan rata-rata jumlah retweet dan favorite tertinggi yaitu mengenai aktivitas perbelanjaan seperti diskon produk dan flash sale. Blibli dapat memaksimalkan konten berupa diskon dan flash sale untuk lebih menarik minat pembeli dan lebih banyak mendapatkan respon positif.

2. Rata-rata terendah jumlah retweet dan favorite yaitu mengenai penawaran barang elektronik aksesoris handphone, Blibli dapat menggunakan konten penawaran barang elektronik ini dengan tambahan diskon atau promo-promo produk yang lebih menarik.

3. Jumlah retweet dan favorite Blibli memiliki nilai rata-rata yang rendah, Blibli dapat meningkatkan jumlahnya dengan menggunakan konten seperti konten kuis berhadiah dan giveaway yang mengharuskan followers menyebarkan tweet tersebut kepada pengguna lain sebagai syarat mengikuti kuis berhadiah tersebut.

Beberapa perbaikan yang dapat dilakukan untuk penelitian selanjutnya adalah menggunakan metode clustering yang lebih efisien serta memiliki kecocokan dengan data yang relatif homogen. Output yang lebih akurat dapat diperoleh dengan menggunakan composite tokenization pada proses tokenizing. Pada tahap preprocessing merupakan tahap yang paling penting dan riskan. Perhatikan pemilihan kata pada tahap stopwords dan penggunaan sintaks diperlukan agar mempermudah proses stemming dan mendapatkan hasil yang lebih akurat dan teliti.

\section{DAFTAR PUSTAKA}

[1] Afuan, L. 2013. Stemming Dokumen Teks Bahasa Indonesia Menggunakan Algoritma Porter. Jurnal Telematika, Vol. 6 No. 2.

[2] Castella, Q. \& Sutton, C., 2014. Word Storms: Multiples of Word Clouds for Visual Comparison of Documents. Seoul, International Conference on World Wide Web, Vol. 1. 
[3] Feldman, R dan Sanger, J. 2007. The Text Mining Handbook. New York: Cambridge University Press.

[4] Go, A., Bhayani, R., dan Huang, L. 2009. Twitter Sentiment Classification using Distant Supervision. Stanford: Stanford University.

[5] Gupta, V dan Lehal, G. S. 2009. A Survey of Text Mining Techniques and Applications. Jurnal Emerging Technologies in Web Intelligence Vol.1, No.1: Hal 607.

[6] Handoyo, R., Mangkudjaja, R., \& Nasution, S. M. 2014. Perbandingan Metode Clustering menggunakan Metode Single Linkage dan K-means pada Pengelompokan Dokumen. Jurnal Sifo Mikroskil, Vol. 15, No.2, Hal: 73-82.

[7] Harjanta, A. J. T. 2015. Preprocessing Text untuk Meminimalisir Kata yang Tidak Berarti dalam Proses Text Mining. Jurnal Informatika UPGRIS Vol. 1.

[8] Hootsuite. 2020. Local Insights. https://datareportal.com/reports/digital-2020indonesia. Diakses: 13 April 2020.

[9] Indraloka, D. S. dan Santosa, B. 2017. Penerapan Text Mining untuk Melakukan Clustering Data Tweet Shopee Indonesia. Jurnal Sains dan Seni ITS, Vol. 6, No.2: 2337-3520.

[10] Laeli, S. 2014. Analisis Cluster dengan Average Linkage Method and Ward's Method untuk Data Responden Nasabah Asuransi Jiwa Unit Link. Yogyakarta: Universitas Negeri Yogyakarta.

[11] Nurhuda, F., Sihwi, S. W., dan Doewes, A. 2013. Analisis Sentimen Masyarakat terhadap Calon Presiden Indonesia 2014 berdasarkan Opini dari Twitter Menggunakan Metode Naive Bayes Classifier. Jurnal IT SMART, Vol. 2, No. 2, Hal: 35-42.

[12] Salton, G. dan Buckley, C. 1988. Term-Weighting Approaches in Automatic Text Retrieval. Jurnal Information Processing and Management Vol.24, No. 5, Hal: 512523.

[13] Supranto, 2004. Analisis Multivariat Arti dan Interpretasi. Jakarta: PT. Rineka Cipta.

[14] Tessem, B., Bjornestad, S., Chen, W. \& Nyre, L., 2015. Word Cloud Visualization of Locative Information. Journal of Location Based Services, Hal. 254-272.

[15] Twitter. 2020. Tentang Twitter. www.twitter.com. Diakses: 14 April 2020.

[16] Utomo, M. S. 2015. Stopword Dinamis dengan Pendekatan Statistik. Jurnal Informatika Upgris, Vol. 1, No. 2.

[17] Wahid, D. H. dan Azhari. 2016. Peringkasan Sentimen Esktraktif di Twitter Menggunakan Hybrid TF-IDF dan Cosine Similarity. Indonesian Journal of Computing and Cybernetics Systems (IJCCS), Vol. 10 , No. 2, Hal: 207-218.

[18] Wu, X. dan Kumar, V. 2009. The Top Ten Algorithms in Data Mining. USA: Chapman and Hall/CRC. 